IBIMA Publishing

IBIMA Business Review

https://ibimapublishing.com/articles/IBIMABR/2019/611983/

Vol. 2019 (2019), Article ID 611983, 11 pages, ISSEN : 1947-3788

DOI : $10.5171 / 2019.611983$

Research Article

\title{
Environment as a Key Factor of Health and Well-Being Tourism Destinations in Five European Countries
}

\author{
${ }^{1}$ Lucie PLZÁKOVÁ and Lucie ${ }^{2}$ CRESPO STUPKOVÁ \\ ${ }^{1}$ Institute of Hospitality Management in Prague, Travel and Tourism Department, \\ Svídnická 506, Prague 8, 181 00, the Czech Republic \\ ${ }^{2}$ CONACYT- Centre of Rural Studies, Michoacán's College, Martínez de Navarrete 505, Col. Las \\ Fuentes, Zamora, Michoacán, Mexico
}

Received date:23 February 2019; Accepted date:26 April 2019; Published date: 16 July 2019

Academic Editor: Amalia Venera Todorut

Copyright (C) 2019. Lucie PLZÁKOVÁ and Lucie CRESPO STUPKOVÁ. Distributed under Creative Commons CC-BY 4.0

\begin{abstract}
Purpose: The purpose of this paper is to determinate key factors of health and well-being (H\&WB) tourism destination expressed by consumers, this means guests (both patients and tourists) in spa destinations or destinations focus on wellness and/or sport activities. Design/methodology/approach: The identification of key factors is based on subjective valuation of each individual consumer. Empirical data were collected through a questionnaire survey in five European countries - United Kingdom, Finland, Germany, Austria and the Czech Republic and were processed by categorical data analysis and exploratory factor analysis. Findings: It was recognised that medical services have proven to be the most important key factor in the assessment and development of health and wellbeing tourism destinations followed by the environment. Accommodation and wellness services are the third and fourth key factors which have significant influence on H\&WB tourism destination. Originality/value: The importance of the environment as the second key factor for evaluation and development of H\&WB tourism destination is a crucial step in the strategic decision-making process. The development of products, choice of price tools and other tasks of the destination management focused on health and human well-being have to respect this fact.
\end{abstract}

Keywords: Health and Well-being, Tourism Destination, Environment, Consumers' motivation and evaluation.

Cite this Article as: Lucie PLZÁKOVÁ and Lucie CRESPO STUPKOVÁ (2019)," Environment as a Key Factor of Health and Well-Being Tourism Destinations in Five European Countries", IBIMA Business Review, Vol. 2019 (2019), Article ID 611983, DOI: 10.5171/2019.611983 


\section{Introduction}

Tourism is a major category of international trade in services and has grown faster than world trade for the past five years. According to Specialized agency of the United Nations World Tourism Organization (UNWTO) (2018), international tourism represents $7 \%$ of the world's exports and $30 \%$ of services exports. As a worldwide export category, tourism ranks third after chemicals and fuels and ahead of automotive products and food. In many developing countries, tourism is the top export category. Tourism has boasted virtually uninterrupted growth over time, despite occasional shocks, demonstrating the sector's strength and resilience. International tourist arrivals have reached 1, 4 billion in 2018 and international tourism receipts earned by destinations worldwide have reached USD 1,332 billion in 2017. The rate of Europe on International tourist arrivals is $51 \%$ and $38 \%$ in the case of International tourism receipts. Europe is the world's most visited continent with the growth $+6 \%$ in 2018 .

The necessity of the study of tourism as a complex socio-ecological system (SESs), which integrates environmental processes and stakeholder behavior, is mentioned in many recent research papers. More qualitative approaches studies of the SESs (Amelung et al., 2016; Frey, 2016; Mancini et al., 2016; Metcalf et al., 2014) can be found then quantitative ones. This study applied quantitative statistical methods to a large data set from five European countries.

In the conditions of individualization of tourism demand, there is a growing need for knowledge of factors that influence the potential tourists' decision at the moment of choosing the destination. If this knowledge is used properly by tourism managers, it will increase both competitiveness and sustainable development of tourism destination.

The use of environment for commercial purposes is a discussion topic of economists, environmentalists, non-profit organizations and politicians at all levels.
The stakeholders have a different opinion about the extent to which the natural resources should be protected, if they can be monetized, who is responsible for their maintenance and whether their consumption is equitable.

\section{Theoretical Background}

A tourism destination is referred to as "a mental category" (Dias and Vasconcelos, 2014) because its definition of a visitor's perspective is given by many psychological factors; every individual has his own expectations, which are very difficult to anticipate in advance. Determining the value of a tourism destination and its key factors is therefore dependent on the perception of each destination element by each individual consumer. Health and wellbeing tourism destination (H\&WB destination) is an area chosen by customers (guest, with either preventive or curative motives) as a travel destination to improve their state of health and/or wellbeing. For better understanding, this type of tourism destination is necessary to identify its aspects. Health is according to The World Health Organization (2006) "a state of complete physical, mental and social well-being". Human health became a part of tourism product. Three different types of tourism can be recognized: health tourism, wellness tourism and medical tourism. United Nations World Tourism Organization defined a term "health tourism" such as "Tourism associated with travel to health spas or resort destinations where the primary purpose is to improve the traveller's physical well-being through a regimen of physical exercise and therapy, dietary control, and medical services relevant to health maintenance" (Rulle, 2008, p. 20). For other definitions of this term see for example Hofer et al. (2012), Hall (2003), Peršić and Vlašić (2018). Medical tourism is when consumers elect to travel across international borders with the intention of receiving some form of medical treatment. Medical tourism is related to the broader notion of health tourism which, in some countries, has longstanding historical antecedents of spa towns and coastal localities, and other 
therapeutic landscapes (Lunt et al., 2011). Wellness tourism defined by Smith and Puczkó (2014, p.208) is when "trips aiming at a state of health featuring the harmony of the body, mind and spirit, selfresponsibility, physical fitness, beauty care, healthy nutrition, relaxation, meditation, mental activity, education, environmental sensitivity and social contacts as fundamental elements". Smith and Puczkó (2009) declare that health tourism is an umbrella for medical tourism and wellness tourism. If we focus on wellness tourism as one of the subsectors of tourism, we can consider that wellness tourism continues to grow faster than global tourism. According to Global Wellness Institute (GWI, 2017), wellness tourism is travel associated with the pursuit of maintaining or enhancing one's personal wellbeing. This market includes two types of wellness tourists: those who take a trip entirely for wellness purposes (primary wellness tourists) and those who seek to engage in wellness activities as part of any kind of trip (secondary wellness tourists). Wellness trips account for $6.5 \%$ of all tourism trips but represent $15.6 \%$ of total tourism expenditures. This is because wellness travelers are high-yield tourists, spending much more per trip than nonwellness travelers. Wellness tourism is heavily concentrated in the key markets of North America, Europe, and Asia-Pacific. Europe is the destination of the largest number of wellness trips, while North America leads in wellness tourism expenditures.

Based on e-handbook Developing a Competitive Health and Well-being Destination (Saari et al., 2014), the key endowed resources for a health and wellbeing tourism destination are nature, natural assets, attractive scenery and environment added by local culture, authenticity and reputation of the destination. Several authors (Sheldon and Park, 2009; Voigt and Pforr, 2013) include nature, culture and heritage in the core resources in the health and well-being industry. Dwyer and Kim (2003) separated the above-mentioned resources from additional or better said created resources such as accommodation services and events. Many studies highlight the positive linkage between nature and human health and well-being. Hartig, Mitchell, de Vries and Frumkni (2014) declare that there is strong evidence that nature has a positive effect on physical and mental health. Recreation is, according to Millennium Ecosystem Assessment (MEA, 2005), one of the non-material benefits of ecosystems which people obtain (accompanied by spiritual enrichment, cognitive development, reflection and aesthetic experiences).Other authors support and add this claim that environmental goods and services meet human needs for recreation, relaxation, therapy and education (see also Díaz, Fargione, Chapin and Tilman, 2006; Bryce et. al, 2016). It can be pointed out that there exist interactions between environmental space with its environmental goods and services and recreational activities that take place within the space (tourist destination).

Due to all these trends in tourism, and especially in wellness tourism, there are some tourist destinations when the number of visitors can outnumber the resident population in some period (in a peak of season). Maintaining a positive relationship with residents, who do not directly benefit from the tourism industry, is important to community sustainability in tourism destinations (Schuster et al., 2011). Tourists and the business sector associated with tourism cause damage to the ecosystem, although unintentional. The main negative externalities of tourism are loss of flora and fauna, loss of biodiversity, higher consumption and contamination of water, higher waste production, airpollution (e.g. Amelung et al. 2016) and carbon footprint (Cadarso et al., 2016). Secondary effect of tourism is the alteration of landscapes from natural vegetation to any other use which typically results in habitat loss, degradation and fragmentation. Unregulated land-use change (from forest or agriculture to urban) associated with the development of tourism infrastructure is also common. The negative environmental effects of tourism have been exposed by Gössling (2002), Gössling and Peeters (2015) and Ruhanen, Weiler, Moyle and McLennan (2015). It is 
essential to find a compromise between the development of tourism, especially health tourism, which is demanding for environmental resources and the preservation of ecosystems, the appearance of the landscape and, last but not least, the cultural identity of the communities.

\section{Methodology}

A questionnaire survey on visitors' motivation to visit H\&WB tourism destination and their satisfaction was used. The analysis uses data obtained from a total of 850 respondents: questionnaires were collected in five countries where health and well-being tourism represents significant part of tourism supply (Austria, Czech Republic, Finland, Germany and United Kingdom) between 2012 and 2014. Distribution by nationality was uniform and 31 were questionnaires discarded as incomplete. The sample selection criterion was the respondents' experience with staying in H\&WB destination. The survey was realized at least in five $H \& W B$ destinations in each country, not only in spa destinations but also in tourism destinations with natural conditions for the wellness and outdoor activities, for example mountain resorts.

The answers to questions: "What was your overall reason to visit this destination?", and "Which services, activities and features do you value most in relation to a given destination?" was statistically analyzed.

The first step was descriptive sample statistics. Subsequently, an exploratory factor analysis (EFA) was conducted performed on an 819 x 18 matrix to identify latent causes of the manifest variable behavior. Matrix consists from 18 items (column a1...a18): Medical treatments, Preventive services, Professional staff, Attractive environment, Outdoor activities, Appearance of landscape, Accommodation 1 (response question \#5), Accommodation 2 (response question \#6), Sauna, Beauty services, Fitness activities, Lower prices, Visiting friends and family, Destination image, Mind and Soul services, Health services, Culture and Healthy food. Correlation coefficients were calculated within the matrix to measure the strength of the relationship among the items. Secondly the items were analyzed with an exploratory factor analysis; factors were constructed from items with a) factor loadings of \pm 0.5 and above b) equivalent at least $10 \%$ explained variation.

The appropriateness of using exploratory factor analysis to our data sample was tested by the Barlett's test and KaiserMeyer-Olkin criteria. Mathematically, factor analysis can be described as a process which examines expression of standardized variables $\mathrm{Xi}$ using a linear combination of a smaller number of hypothetical factors $\mathrm{Fj}$ as follows:

$\mathrm{Xi}=$ ai1 $\mathrm{F} 1+$ ai2 $\mathrm{F} 2+\mathrm{ai} 3 \mathrm{~F} 3+\ldots+$ aim Fm + ei

where $\mathrm{i}=1,2,3, \ldots \mathrm{k}$, where $\mathrm{k}$ is the number of manifest variables, $m$ the number of factors, aim represents the factor loading between $\mathrm{F}$ and $\mathrm{X}$ and ei a specific (error, residual) part of the variable $\mathrm{X} i$, of which we assume that the correlation of all the factors is zero. In doing so, we require $\mathrm{m}<\mathrm{n}$.

Exploratory factor analysis was performed using Principal Component Analysis as the method of extraction. Varimax orthogonal rotation was used with the goal of obtaining a solution that is easier to interpret than the initial factor extraction. The purpose of the rotation factors is that originally scattered points are seen as possibly clinging to one of the extracted factors.

The last third step, after identification of the environment as the second key factor of H\&WB destination, analysis of categorical variables was completed for search if age, education or nationality affect the respondents' valuation of the environment.

\section{Results}

Respondents were in 72 percent female and in 28 percent male. More than 90 percent of respondents are between the 
ages of 21 and 70 and more than 80 percent has between secondary and master education degree (Table 1).

Table 1: Characteristics of sample

\begin{tabular}{|l|l|l|l|}
\hline Age & $\%$ & Education degree & $\%$ \\
\hline$<\mathbf{2 0}$ & 3.6 & Primary & 14.0 \\
\hline $\mathbf{2 1 - 3 0}$ & 20.3 & Secondary & 33.2 \\
\hline $\mathbf{3 1 - 4 0}$ & 16.1 & Bachelor & 28.9 \\
\hline $\mathbf{4 1 - 5 0}$ & 20.3 & Master & 18.4 \\
\hline $\mathbf{5 1 - 6 0}$ & 20.3 & Doctoral & 5.5 \\
\hline $\mathbf{6 1 - 7 0}$ & 14.2 & & \\
\hline $\mathbf{7 1 - 8 0}$ & 3.9 & & \\
\hline $\mathbf{8 1 <}$ & 1.3 & & \\
\hline
\end{tabular}

Source: Own, 2018, based on research project WelDest

The Principal Components Analysis (PCA) was chosen due to type of data and their properties recommended by Gaskin and Hapell (2014). Through Barlett's sphericity test $(\mathrm{p}<0.01)$ and the Kaiser-Meyer-Olkin (the KMO) criteria where KMO $=0,664$, the null hypothesis of a unit correlation matrix was rejected, which means that the use of factor analysis is appropriate for our data sample.

As a result of the calculation (by EFA), the overall highest variable share in the model is attributed to Therapeutic treatments. Variables connected with Spa treatments, Attractive environment, Landscape and its appearance have the highest proportion of the total variability explanation model. the lowest impact on the model have variables related to Healthy food and Culture (Table 2). On the other side, variables Healthy food and Culture have the lowest proportion of the total variability explanation model.
Next step was to determine the number of factors that will be included in the final model. Decisions on the number of factors were performed by calculating the totally explained variability of the model. During decision making process on the number of factors the processor's subjective judgment and interpretability play a role. Per the Kaiser rule (component with total initial eigenvalues greater than 1 may be part of the model), up to eight factors may be selected. According the Scree graph should be rather selected only 4 factors. For the number of factors, the authors determined the threshold minimum proportion of the total variability (Initial eigenvalues as a percentage of variance) of $10 \%$ rounded. Four factors were chosen that offer explanation of $47.4 \%$ of the total variability of the model (Table 2). It can be judged that the share of variability of the model, which is explained by the items, is low. However, tourism is characterized by high level of multi-causality, so almost half of variability is a successful result. 
Table 2: Results of explanatory factor analysis

\begin{tabular}{|l|l|l|l|l|l|}
\hline Factor & Factor name & $\begin{array}{l}\text { \% variation } \\
\text { explained }\end{array}$ & Eigenvalue & Item & Loading \\
\hline 1 & Medical services & 14.8 & 2.8 & Medical treatments & 0.73 \\
\hline & & & & Preventive services & 0.56 \\
\hline & & & & Professional staff & 0.58 \\
\hline 2 & Environment & 12.4 & 2.4 & $\begin{array}{l}\text { Attractive } \\
\text { environment }\end{array}$ & 0.70 \\
\hline & & & & Outdoor activities & 0.64 \\
\hline & & & & Natural scenery & 0.69 \\
\hline 4 & Accommodation & 10.4 & 2.0 & Accommodation $(1)$ & 0.69 \\
\hline & & & & Accommodation $(2)$ & 0.60 \\
\hline & Wellness services & 9.8 & 1.9 & Sauna & 0.62 \\
\hline
\end{tabular}

Source: Own, 2018, based on research project WelDest

Key factors are, in the order of importance: Medical services, Environment, Accommodation and Wellness services. Environment, along with the traditional $\mathrm{H} \& W B$ services, is another significant one.

Chi-square test of independence within the analysis of categorical variables showed no significant relationships between gender and education variables and environment, however, the influence of nationality was proved. Results reveal that the environment is the second most important factor in decision-making before travel; following Health services; and it is important for $47.9 \%$ of the respondents. The importance of environment as a motivation pull factor shows Figure 1. The environment was also the second most appreciated factor after visitors' return, mentioned by $37.8 \%$ of respondents.

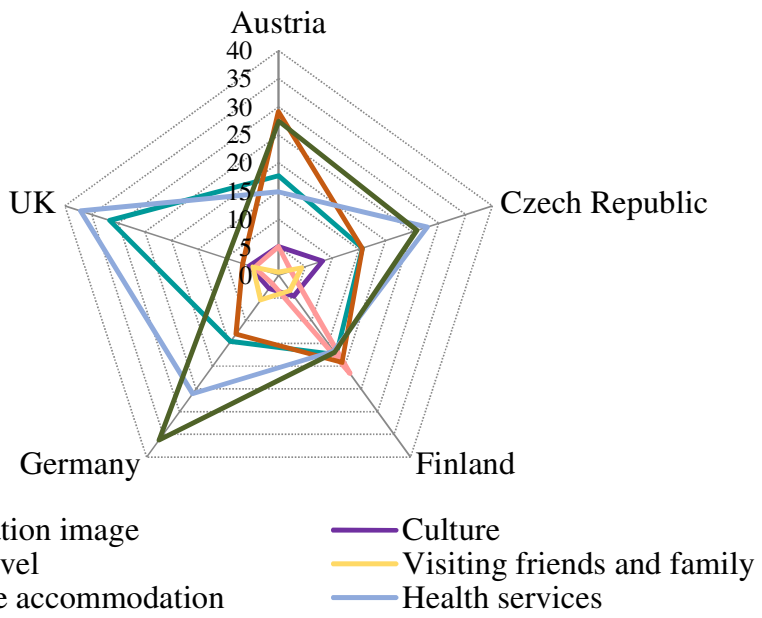

Fig. 1: Motivation factors before traveling (in \%)

Source: Own, 2018, based on research project WelDest 
As can be seen from the figure, natural scenery (part of factor environment) is assessed very differently across nationalities as was mentioned above. Germans consider the nature scenery as the most important factor. For Czechs and Austrians, the natural scenery is the second most important reason, but for the residents of the United Kingdom it is on the third place and for Finns on the fourth. Finns value more price level and suitable accommodation and Britons value more health services and destination image then nature scenery. The values of Germany and UK are statistically significantly different of the mean; moreover, the standard deviation for natural scenery is the higher (10.2), what indicates the high heterogeneity.

\section{Discussion}

Traditional theories (e. g. Kotler et al., 2016) divide a product into three parts (core benefit, actual product and augmented product). From the health and well-being tourism point of view, the medical services could be considered as a core benefit of H\&WB destination's product; accommodation and food and beverage services, as others supporting tourism service, represent the second layer of a product and an augmented product is formed by bio-climatic conditions.

According to the research results, medical services are the most valued and requested by visitors, which is in line with the mentioned theory. Environment, included in augmented product, is the second most important factor. Accommodation and wellness services were not considered as important as theories suppose. Surprisingly, the lowest importance has variables related to Healthy food and Culture in destination, which are generally considered important in H\&WB destinations.

Conclusion, that environment in its entirety belongs, among the key factors of tourist destinations underline also other authors: for example, Rigall-I-Torrent and Fluvià (2007). Also other authors, for example
Rigall-I-Torrent and Fluvià (2007), underline "environment" as the key factor of tourist destinations. Tomasovic et al. (2015) state that the natural and geographical characteristics of the health tourism location (local climate conditions, available natural remedies, and natural attractions) are factors that significantly influence the preferences of the elderly $(65+)$ in their decision whether to select tourism services. Bryce et al. (2016) focused on the subjective well-being indicators for large-scale assessment of cultural ecosystem services. They used EFA to obtain the key factors of individual wellbeing indicators and the result was: 1 . engagement and interaction with nature; 2 . place identity; and 3. therapeutic value.

Perception of the environment across nationalities attracts the authors' attention, so they decided to examine the issue more closely. The comparison of research results with the Eurostat Environmental Indicators (Table 3 in Appendix), that focused on degree of naturalness of the landscape (using the Hemeroby index) and social awareness of the agrarian landscape, was done. The indicators can explain how valuable the environment is for residents of different countries, and what social awareness about the landscape they have. The Hemeroby index measures the degree of human influence on the landscape, where the lowest value represents natural unspoiled landscape and the highest values represent completely artificial and humandisturbed landscapes. The least humandisturbed landscape is in Austria and the most disturbed is in Germany. The last three levels of disturbed landscapes together amount to $95 \%$ of the country's area in Germany, $89 \%$ in Finland, $88 \%$ in Czech Republic and $74 \%$ in the UK (see Table 3 in Appendix). This information can explain why natural landscape is attractive for the Germans and Czechs: it is very rare.

In the case of Austrians, the explanation of their high valuation of the environment is different: they have a high social awareness of the landscape. Social awareness 
indicators of the countryside have three components, shown in the second part of Table 3: quality schemes, protected agriculture and tourism. Each component has a different importance across countries. The tourism component is the most important one in three states Austria, the UK and Finland. The protected agriculture component is the most important one in Germany. Overall, the index of social awareness is highest in Austria, followed by Germany and the UK.

\section{Conclusions}

Medical services have proven to be the most important key factor in the assessment and development of health and well-being tourism destinations. But also, medical services include natural resources in the form of peloids, treatment gas or mineral waters. Research has shown that environment has an irreplaceable role in fulfilling the essence of health and well-being tourism. Crossnationals' differences were identified in case of factors before traveling, when environment, as a pull factor of tourist motivation, is very strong in the case of German, Czech and Austrian tourists. This result was confronted with the natural conditions in the observed countries and social awareness of its inhabitants.

The identification of the environment as the key factor is an important first step in the strategic decision-making process from which is derived development of products, choice of price tools and other tasks of the destination management. Authors proposal is to develop strategies which combine both requirements for tourism development and natural wealth preservation. The possible solutions can be institutional with special care about the participation of both - residents and visitors - in the decision making process.

The main institutional arrangements related to tourism destinations are taxes and laws. Financial requirements for natural resources restoration and conservation are national budgets expenditure items. Responsibility for sustainable tourism development, however, should respect the subsidiarity principle: management and financing of the tourism sustainability should be proportionally divided among various levels of public administration, as well as between public and business sectors. The tourism destinations should themselves provide financial resources to support and maintain the environment in such a condition to prevent its devastation. One source of funding could be revenues from local taxes directly related to tourism. An example might be Austria and Germany, where local fees set at the states level, and revenues that municipalities receive from them are further reinvested into tourism, including care of the environment.

Improvement of laws should be concerned on tightening supervision over land-use change in tourism destinations, welldefined boundaries of the use of natural resources, monitoring, graduated sanctions for violated rules, rapid and lowcost conflict-resolution mechanisms and compliance with mandatory environmental regulations and standards. Collective-choice arrangements and participation of the residents on the management of the natural resources is essential for ensuring equilibrium between benefits and costs.

The limitation of use of natural resources results in lower economic growth in the short term, so it can be considered as opportunity cost and calculated as the sum of lost profits. The basic rule is that the benefits must outweigh the costs in the long term. Specific actions that can be implemented in the short term are: improving energy and water efficiency, reduction of consumption of water and energy, use of renewable energy sources, minimization of wastes, recycling and restriction of access into endangered areas. However, the protection of natural resources exceeds local administration capabilities, so it should be solved in the higher administration level and with longterm perspective. 


\section{Acknowledgements}

"This paper is based on data of WelDest (Health and Well-being in Tourism Destination) project which was supported by the Education, Audiovisual and Culture Executive Agency of European Commission under Grant 527775-LLP-1-2012-1-FIERASMUS-ECUE." The Higher Education Institute partners of the project were: Turku University of Applied Sciences, Finland; University College Birmingham, United Kingdom; FH JOANNEUM University of Applied Sciences, Austria; The Institute of Hospitality Management, Czech Republic and University of Applied Sciences in Eberswalde, Germany.

\section{References}

1. Amelung, B., Student, J., Nicholls, S., Lamers, M., Baggio, R., Boavida-Portugal, I....and Balbi, S. (2016) 'The value of agentbased modelling for assessing tourismenvironment interactions in the Anthropocene', Current Opinion in Environmental Sustainability, 23: pp.46-53

2. Barlett, M. S. (1950) 'Test of significance in factor analysis', British Journal of Statistical Psychology, 3:pp. 77 85

3. Bryce, R., Irvine, K. N., Church, A., Fish, R., Ranger, S. and Kenter, J. O. (2016) 'Subjective well-being indicators for largescale assessment of cultural ecosystem services', Ecosystem Services, 21:pp.258 269

4. Cerny, C. A., and Kaiser, H.F. (1977) 'A study of a measure of sampling adequacy for factor-analytic correlation matrices",Multivariate Behavioral Research, 12:pp. 43-47

5. Cadarso, M. A., Gomez, N., Lopez, L. A., and Tobarra, M. A. (2016) 'Calculating tourism's carbon footprint: measuring the impact of Investments', Journal of Cleaner Production, 111: pp.529- 537

6. Dias, F., and Vasconcelos, J. (2014) Destination brand index: A new method for assessment of destination competitiveness in Tourism research in a changing world, GITUR, Portugal

7. Díaz, S., Fargione, J., Chapin, F.S., and Tilman, D. (2006) 'Biodiversity loss threatens human well-being', PLoS Biology,4, 8: pp. 1300-1305

8. Dwyer, L., and Kim, Ch. (2003) 'Destination competitiveness: determinants and indicators', Current Issus in Tourism, Taylor and Francis Group, 6/5:pp 369-414

9. EUROSTAT (2012) 'Agrienvironmental indicator - landscape state and diversity', [accessed 09August 2018] Available at: http://ec.europa.eu/eurostat/statisticsexplained/index.php/Agrienvironmental_indicator__landscape_state_and_diversity

10. Frey, U. J. (2017) 'A synthesis of key factors for sustainability in socialecological systems', Sustainability Science, 12, 4: pp. 507-519

11. Gaskin, C.J., and Hapell, B. (2014) 'On exploratory factor analysis: A review of recent evidence, an assessment of current practice, and recommendations for future use', International Journal of Nursing Studies, 51: pp.511-521

12. Global Wellness Institute (2017) 'Global Wellness Economy Monitor January 2017', [accessed 10 September 2018] Aavailable at: http://www.globalwellnessinstitute.org/

13. Gössling, S. (2002) 'Global environmental consequences of tourism', Global Environonmental Change,12, 4: pp. 283-302

14. Gössling, S., and Peeters, P. (2015) 'Assessing tourism's global environmental impact 1900-2050', Journal of Sustainable Tourism, 23, 5: pp. 639-659

15. Hall, C.M. (2003) 'Health and SPA tourism' in Hudson, S. (ed.) International Sports \& Adventure Tourism, New York, Haworth Press, 273292 
16. Hartig, T., Mitchell, R., de Vries, S., and Frumkni, H. (2014) 'Nature and health', Annual Review of Public Health, 35:pp. 207 $-228$

17. Hofer, S., Honegger, F., and Hubeli, J. (2012) 'Health tourism: definition focused on the Swiss market and conceptualisation of health(i)ness', ,Journal of Health Organization and Management,26,1: pp. 6080

18. Kaiser, H.F. (1958) 'The varimax criterion for analytic rotation in factor analysis', Psychometrika, 23: pp.187-200

19. Kotler, P., Bowen, J., Makens, J., Baloglu, S. (2016) Marketing for Hospitality and Tourism, Pearson

20. Lunt, N., Smith, R., Exworthy, M., Green, S., Horsfall, D. and Mannion, R. (2011) Medical Tourism: Treatments, Markets and Health System Implications: A scoping review. OECD, Paris.

21. Millennium Ecosystem Assessment (2005) Ecosystems and human well-being: synthesis report. Island Press, Washington DC

22. Mancini, F., Coghill, G. M., and Lusseau, D. (2016) 'Using qualitative models to define sustainable management for the commons in data poor conditions', Environmental Science \& Policy 67: pp. 5260

23. Metcalf, S.J., Dambacher, J.M., Rogers, P., Loneragan, N.,and Gaughan, D.J. (2014) 'Identifying key dynamics and ideal governance structures for successful ecological management', Environmental Science \& Policy,37: pp. 34-49

24. Peršić, M., and Vlašić, D. (2018) 'Health tourism development - specifics of Croatian health/spas/healing resorts and special hospitals - state and possibilities' chapter in book Marinov, V., Vodenska, M., Assenova, M., and Dogramadjieva, E. (2018) Traditions and Innovations in Contemporary Tourism. Cambridge Scholars Publishing
25. Rigall-I-Torrent, R., and Modest Fluvià, M. (2007) 'Public goods in tourism municipalities: formal analysis, empirical evidence an implications for sustainable development', Tourism Economics,13 (3):pp. 361-378

26. Ruhanen, L., Weiler, B., Moyle, B. D., and McLennan, C.J. (2015) 'Trends and patterns in sustainable tourism research: a 25-year bibliometric analysis', Journal of Sustainable Tourism,23 (4):pp. 517-535

27. Rulle, M. (2008) Der Gesundheitstourismus in Europa: Entwicklungstendenzen und Diversifikations-strategien. München, Germany \& Wien, Austria: Profil Verlag.

28. Saari, S., Tuominen, T., Dvorak, D., Binder, D., Illing, K., Husak, Ch.,....and Schmidt, R. (2014), Developing a Competitive Health and Well-being Destination. Turku, Finland

29. Sheldon P.J. and Park, S.-Y. (2009) 'Development of sustainable wellness destination' In Bushell, R. and Sheldon, P. J. (2009) Wellness and Tourism-Mind, Body, Spirit, Place. Cognizant Communication Corporation. Chapter 6

30. Schuster R. M., Sullivan L. E., Kuehn D. M., and Morais D. B. (2011) 'Relationships among Resident Participation in Nature and Heritage Tourism Activities, Place Attachment, and Sustainability in three Hudson River Valley Communities', Journal of Park and Recreation Administration,29 (3): pp. 55-69

31. Smith, M., K., and Puczkó, L. (2009) Health and wellness tourism. 2nd edition, Oxford, UK: ButterworthHeinemann.

32. Smith, M., K., and Puczkó, L. (2014) Health, Tourism and Hospitality: Spas, Wellness and Medical Travel. Routledge, $\mathrm{p}$. 508

33. Tomasovic Mrcela, N., Borovac,J. A., Vrdoljak,D., Grazio,S., Tikvica, L. A., and Tomek-Roksandic, S. (2015) 'When elders choose: Which factors could influence the decision-making among elderly in the 
selection of health tourism services?', Medical Hypotheses, 85:pp. 898-904

34. Voigt, C., and Pforr, C. (Eds.) (2013) Wellness tourism: A destination perspective. Routledge.

35. UNWTO (2018) Tourism Highlights: 2018 Edition, Madrid, Spain, [accessed 17 February 2019] Available at:

\section{Notes}

1. Barlett's sphericity test is used to test the null hypothesis about the homoscedasticity of variances it means that the correlation matrix is identity matrix or sometimes called as unit matrix. If we refuse this null hypothesis, then a factor analysis makes sense (Barlett, 1950).

2. Kaiser-Meyer-Olkin criterion (also used label rate) is also used to assess suitability of factor analysis. Criterion balanced by the quotient of the sum of the squared correlation coefficient to the sum of the squared of correlation coefficients and partial and takes values between 0 and 1 (factor analysis less than 0.5 is meaningless) (Cerny and Kaiser, 1977). https://www.eunwto.org/doi/pdf/10.18111/978928441 9876

36. WHO (2006) Basic documents. 45th ed. Geneva: World Health Organization, [accessed 17August 2018] Available at: http://www.who.int/governance/eb/who_ constitution_en.pdf
3. Varimax method is performed in the second phase of factor analysis and is used to transform factors using their rotation. The aim of the method is to find position factors, the factor loading becomes either close to zero or one. This means that each manifest variable is strongly correlated with only some factors and with other factors is correlated weakly. Finding such factors is used to rank the interpretation of outputs more easily (Kaiser, 1958).

4. The research was done in 151 marine protected areas in the United Kingdom. They set up 15 indicators to assess cultural wellbeing and they collected 1,220 questionnaires (the respondents were recreational divers and anglers).

\section{Appendix}

Table 3: Agri-environmental indicators

\begin{tabular}{|c|c|c|c|c|c|}
\hline Indicator / Country & Finland & $U K$ & Germany & Austria & $\begin{array}{l}\text { Czech } \\
\text { Republic }\end{array}$ \\
\hline $\begin{array}{l}\text { Hemeroby index (\% of area) } \\
-\quad \text { Close to natural, semi-natural }\end{array}$ & 0 & 8 & 2 & 15 & 2 \\
\hline - $\quad$ Relatively far from natural, agroforestry & 11 & 18 & 3 & 17 & 10 \\
\hline $\begin{array}{l}\text { Relatively far from natural, intensive } \\
\text { grassland }\end{array}$ & 33 & 32 & 23 & 20 & 18 \\
\hline - $\quad$ Far from natural, intensive arable land & 45 & 10 & 20 & 25 & 44 \\
\hline Far from natural, cereal monocultures & 11 & 32 & 52 & 23 & 26 \\
\hline $\begin{array}{l}\text { Contribution of the three components to the } \\
\text { total social awareness of the agrarian } \\
\text { landscape indicator (0-10 range) } \\
-\quad \text { Quality schemes component }\end{array}$ & 0.2 & 0.4 & 0.7 & 2.3 & 0.4 \\
\hline - $\quad$ Protected agriculture component & 1.0 & 3.3 & 6.3 & 3.5 & 2.1 \\
\hline - $\quad$ Tourism component & 3.1 & 3.4 & 2.5 & 6.0 & 1.8 \\
\hline
\end{tabular}

Sources: EUROSTAT, 2012 